\title{
Human Computer Calendar for ZERO to INFINITE
}

\author{
Dulal Chandra Samanta ${ }^{1}$, Debabrata Samanta ${ }^{2}$ \\ ${ }^{1}$ Bhupatinagar, Chaitanyapur, West Bengal, India \\ ${ }^{2}$ Department of CSE, National Institute of Technology, Durgapur, West Bengal, India
}

\begin{abstract}
Calendar is the key of our life. In every aspect of our life we need to follow it. It is not possible to keep calendar of the range ZERO to INFINITE. Generally we can have calendar up-to 300 years from the current one. There is some formula to calculate the year/month etc. but they have some limitation, they cannot be applicable for ZERO to INFINITE calendar. In this paper, we proposed a novel methodology to extract the day, month, year from ZERO to INFINITE range of calendar with a few seconds.
\end{abstract}

Keywords: Mid-point of the Operator, leap - year.

\section{Introduction}

Have you ever imagined the vastness of the world of knowledge, you could easily be lost in between the vastness and depth of it. So easily and unmindfully that you would never be able to understand whether are you thinking or just wondering? Mathematics is just like that for me. I like this subject from every corner of my heart (and obviously, mind). And then I came to know its mysteries. So interesting and fascinating they seemed. Here is just a single one. More will be waiting latter.

What if I now ask you can you tell me exactly the day Shivaji died? Many History students would rather tell, "Ya. Why not? It'd be a..." Yes another boring date. But my question was something different. I asked can you tell me the exact day. I mean whether it was Monday or Tuesday or the other??

Isn't that interesting? You'll be surprised to know that you can, actually tell exactly and accurately the day. By doing some boring huge calculations? No. Not at all. By just following my words in only 1 minutes.

Ya. I challenge you.

Do you accept?

Then let's start the tour.

II. Proposed Diagram

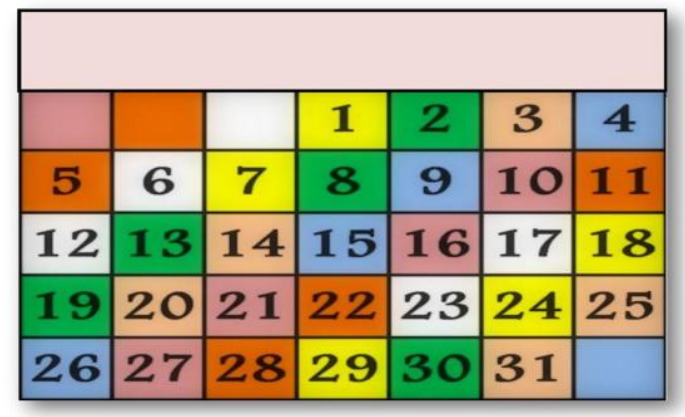

From unity to infinity

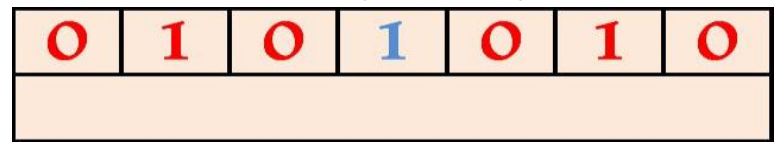

III. PROPOSED METHODOLOGY

Algorithm 1:

1. we'll first convert any year into a 4 digit number, suppose - abcd

2. Next to this, the 4 digit number is divided into two sets of numbers - one with the left sided 2 digits and the other with the rest.

For instance, 


\begin{tabular}{|l|l|}
\hline $1^{\text {st }}$ Set & $2^{\text {nd }}$ Set \\
\hline $\mathrm{ab}$ & $\mathrm{cd}$ \\
\hline
\end{tabular}

3. Then the first set is divided by 4 , and the remainder is selected (4 possibilities thus comes out $-0,1,2,3)$ and their values are determined with the help of Moving Scale No. 2.

4.

$$
C_{x}=4 n+r
$$

Where, $x=(0$ to 3$)$ and $n=(0$ to 24$)$

When,
$\mathrm{x}=0$
then
$\mathrm{n}=0$ to 6
$\mathrm{x}=1$
$\mathrm{n}=7$ to 13

$\mathrm{x}=2$

$\mathrm{n}=14$ to 20

$\mathrm{x}=3$

$\mathrm{n}=21$ to 24

Here, for every value of $\mathrm{n}, \mathrm{r}$ is always $1,2,3,4$.

$$
1 \leq \mathrm{C}_{0} \leq 28<\mathrm{C}_{1} \leq 56<\mathrm{C}_{2} \leq 84<\mathrm{C}_{3} \leq 99
$$

How to convert $\mathrm{C}_{\mathrm{x}}$ to $\mathrm{C}_{\mathrm{p}}$ ?

When, $x=0$, i.e,

The Rule: -

$$
1 \leq \mathrm{C}_{0} \leq 28
$$

$\begin{array}{llllll}\mathrm{n}= & 0 & 1 & 2 & 3\end{array}$

45

$\mathrm{C}_{\mathrm{p}}=$

$(\mathrm{N}+1)$

(N-5)

$(\mathrm{N}-10)$

$\{(\mathrm{N}-20)+4\}$

When, $x=1,2,3$ i.e,

\section{$28<\mathrm{C}_{1} \leq 56<\mathrm{C}_{2} \leq 84<\mathrm{C}_{3} \leq 99$}

For, $\mathrm{n}=7$ to 24 ,

It's very much harder to convert $C_{x(1,2,3)}$ to $C_{p}$. Therefore, we'll first transform them to $C_{0}$ and then to $C_{p}$.

The Rule to convert $\mathrm{C}_{\mathrm{x}(1,2,3)}$ to $\mathrm{C}_{0}$ : - 
When $\mathrm{x}=1,2,3$

Therefore,
$\mathrm{C}_{1}$
$\left(\mathrm{C}_{1}-30\right)+2=\mathrm{C}_{0}$
$\mathrm{C}_{2}$
$\left(\mathrm{C}_{2}-60\right)+4=\mathrm{C}_{0}$
$\mathrm{C}_{3}$
$\left(\mathrm{C}_{3}-90\right)+6=\mathrm{C}_{0}$
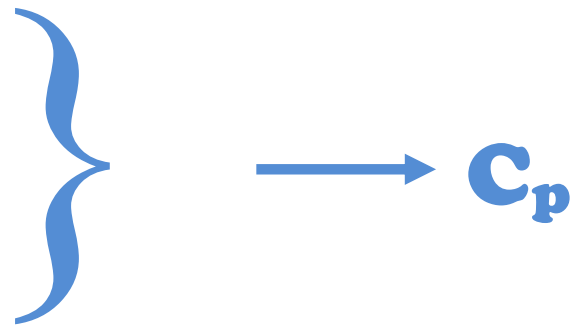

5. Following this, if the second set becomes general, then 3 or if it becomes leap - year, then 4 is added to that. 6. Then the two sets are added and their result is placed at the mid-point of the Operator.

\section{Algorithm 2:}

Next to this, using the definite formulae the values of $\mathrm{d}, \mathrm{M}, \mathrm{D}$, and $\mathrm{Y}$ is determined. Where,

$$
\begin{aligned}
& \mathrm{d}=\text { Day } \\
& \mathrm{M}=\text { Month } \\
& \mathrm{D}=\text { Date } \\
& \mathrm{Y}=\text { Year }
\end{aligned}
$$

* $\mathrm{Y}_{\mathrm{X}(\mathrm{n})}$ form:

$\mathrm{x}_{\mathrm{g}}=\mathrm{C}[\mathrm{M}(\mathrm{P})-(\mathrm{n}+3)]=\mathrm{C}(\mathrm{r})$

Therefore, $x_{1}=C(r-1)$

* $\mathrm{Y}_{\mathrm{n}(\mathrm{x})}$ form:

$\mathrm{x}_{\mathrm{g}}=\mathrm{M}(\mathrm{P})-\mathrm{C}(\mathrm{n})=\mathrm{K}$

Therefore, $\mathrm{x}_{1}=\mathrm{K}-1$

For January and February, $\mathrm{x}_{\mathrm{g}}=\mathrm{x}_{\mathrm{l}}$

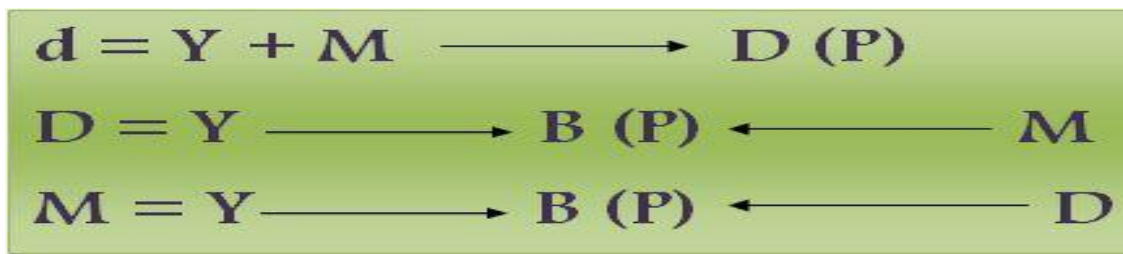

And

C means to convert

$\mathrm{P}$ means position

M (P) means Middle Position

\section{CONCLUSION}

In this paper, we proposed a novel methodology to extract the day, month, year from ZERO to INFINITE range of calendar with a few seconds. This methodology mainly depends on mid-point of the Operator. Anyone can easily calculate day, month, and year from ZERO to INFINITE range of calendar with respect to color detection. The result from the preliminary study indicated that the proposed strategy is effective to assess calendar problem in more precisely.

\section{REFERENCES}

[1] www.scribd.com/.../11707676-An-Exploratory-Study-of-Personal-Calendar-Use.

[2] iris.usc.edu/information/Iris-Conferences.html

[3] www.cs.utep.edu/novick/courses/CS5317/Schedule.pdf. 